\title{
Desenvolvimento de plantas de milho submetidas a doses de adubação NPK mineral e organomineral
}

\author{
Development of maize plants submitted to NPK mineral and organomineral fertilization doses \\ Desarrollo de plantas de maíz sometidas a dosis de fertilización mineral y organomineral NPK
}

Recebido: 16/04/2021 | Revisado: 25/04/2021 | Aceito: 27/04/2021 | Publicado: 11/05/2021

Jenifer Kelly Ferreira Santos

ORCID: https://orcid.org/0000-0001-9763-7478 Instituto Federal de Educação, Ciência e Tecnologia Goiano, Brasil

E-mail: jeniferagro@gmail.com

Fernando Rodrigues Cabral Filho

ORCID: https://orcid.org/0000-0002-5090-5946 Instituto Federal de Educação, Ciência e Tecnologia Goiano, Brasil

E-mail: fernandorcfilho@hotmail.com

Alefe Viana Souza Bastos

ORCID: https://orcid.org/0000-0002-0349-2421 Instituto Federal de Educação, Ciência e Tecnologia Goiano, Brasil

E-mail: alefe_viana@hotmail.com

Fernando Nobre Cunha

ORCID: https://orcid.org/0000-0001-8489-7625 Instituto Federal de Educação, Ciência e Tecnologia Goiano, Brasil

E-mail: fernandonobrecunha@ hotmail.com

Marconi Batista Teixeira

ORCID: https://orcid.org/0000-0002-0152-256X Instituto Federal de Educação, Ciência e Tecnologia Goiano, Brasil

E-mail: marconi.teixeira@ifgoiano.edu.br

Edson Cabral da Silva

ORCID: https://orcid.org/0000-0002-1813-490X Instituto Federal de Educação, Ciência e Tecnologia Goiano, Brasil E-mail: edsoncabralsilva@gmail.com

Evaldo Alves dos Santos

ORCID: https://orcid.org/0000-0001-5610-4288 Instituto Federal de Educação, Ciência e Tecnologia Goiano, Brasil E-mail: evaldo0.santos@gmail.com

Vitor Marques Vidal

ORCID: https://orcid.org/0000-0001-5179-6684 Instituto Federal de Educação, Ciência e Tecnologia Goiano, Brasil E-mail: vmarquesvidal@gmail.com

Wilker Alves Morais

ORCID: https://orcid.org/0000-0003-2336-6518 Instituto Federal de Educação, Ciência e Tecnologia Goiano, Brasil E-mail:wilker.alves.morais@gmail.com

Roniel Geraldo Avila

ORCID: https://orcid.org/0000-0002-8909-7907 Instituto Federal de Educação, Ciência e Tecnologia Goiano, Brasil E-mail: ronielavila10@gmail.com

Frederico Antonio Loureiro Soares

ORCID: https://orcid.org/0000-0002-4152-5087 Instituto Federal de Educação, Ciência e Tecnologia Goiano, Brasil E-mail: frederico.soares@ifgoiano.edu.br

\section{Resumo}

Práticas alternativas de manejo são necessárias para minimizar a necessidade por fertilizantes minerais em sistemas de cultivos com culturas não leguminosas. Os níveis de adubação empregados, em especial com os macronutrientes primários NPK, geralmente influenciam a taxa de crescimento e o desenvolvimento do milho, com reflexos positivos na produção da cultura. Neste estudo, objetivou-se avaliar o efeito de doses de adubação e fontes de formulados mineral e organomineral no crescimento, desenvolvimento e leitura de SPAD de plantas de milho. O experimento foi realizado em vasos plásticos, dispostos a céu aberto, preenchidos com $25 \mathrm{~L}$ de solo, coletado da camada de 0 a 0,20 m, de um Latossolo Vermelho distrófico de Cerrado, na Fazenda Experimental do Instituto Federal Goiano, Campus Rio Verde - GO. O delineamento experimental utilizado foi de blocos ao acaso em esquema fatorial $5 \times 2$, com quatro repetições, constituídos por cinco doses de formulado NPK 04-14-08 (0, 150, 300, 450, $600 \mathrm{~kg}^{-1}$ do produto, 
equivalente para vaso) e duas fontes de fertilizantes mineral e organomineral da formulação, 04-14-08. Nas plantas, foram realizadas avaliações das características agronômicas, a cada quinze dias (30, 45, 65, 75 dias após emergência), de altura de planta, diâmetro do colmo, número de folhas, leitura SPAD e área foliar. A dose de $600 \mathrm{~kg} \mathrm{ha}^{-1} \mathrm{do}$ formulado 04-14-08 proporciona o melhor desenvolvimento de diâmetro do colmo e altura de planta. A fonte organomineral proporciona maior altura de planta de milho, número de folhas e área foliar. O fertilizante organomineral apresenta eficiência para garantir o crescimento e desenvolvimento do milho.

Palavras-chave: Zea mays; Macronutrientes; Fertilizantes; Nutrição de plantas.

\begin{abstract}
Alternative management practices are necessary to minimize the need for mineral fertilizers in crop systems with nonleguminous crops. The levels of fertilization used, especially with the primary macronutrients NPK, generally influence the growth rate and the development of corn, with positive effects on the production of the crop. This study aimed to evaluate the effect of fertilizer doses and sources of mineral and organomineral formulations on the growth, development and reading of SPAD of corn plants. The experiment was carried out in plastic pots, arranged in the open, filled with $25 \mathrm{~L}$ of soil, collected from the 0 to 0.20 m layer of a dystrophic Red Latosol in the Cerrado, at the Experimental Farm of the Federal Goiano Institute, Rio Verde Campus - GO. The experimental design used was randomized blocks in a $5 \times 2$ factorial scheme, with four replications, consisting of five doses of formulated NPK $04-$ 14-08 $\left(0,150,300,450,600 \mathrm{~kg} \mathrm{ha}^{-1}\right.$ of the product, equivalent to pot) ) and two sources of mineral and organomineral fertilizers from the formulation, 04-14-08. In the plants, evaluations of the agronomic characteristics were carried out, every fifteen days $(30,45,65,75$ days after emergence), of plant height, stem diameter, number of leaves, SPAD reading and leaf area. The dose of $600 \mathrm{~kg} \mathrm{ha}^{-1}$ of the formulation 04-14-08 provides the best development of stem diameter and plant height. The organomineral source provides a higher corn plant height, number of leaves and leaf area. Organomineral fertilizer is efficient to ensure the growth and development of corn.
\end{abstract}

Keywords: Zea mays; Macronutrients; Fertilizers; Plant nutrition.

\title{
Resumen
}

Se necesitan prácticas de manejo alternativas para minimizar la necesidad de fertilizantes minerales en sistemas de cultivo con cultivos no leguminosos. Los niveles de fertilización utilizados, especialmente con los macronutrientes primarios NPK, generalmente influyen en la tasa de crecimiento y desarrollo del maíz, con efectos positivos en la producción del cultivo. Este estudio tuvo como objetivo evaluar el efecto de dosis de fertilizantes y fuentes de formulaciones minerales y organominerales sobre el crecimiento, desarrollo y lectura de SPAD de plantas de maíz. El experimento se realizó en macetas de plástico, dispuestas al aire libre, llenas de 25 L de tierra, recolectada de la capa de 0 a 0,20 m de un Latosol Rojo distrófico en el Cerrado, en la Finca Experimental del Instituto Federal Goiano, Río Verde. Campus - GO. El diseño experimental utilizado fue bloques al azar en un esquema factorial $5 \times 2$, con cuatro

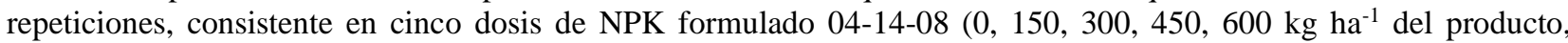
equivalente a maceta )) y dos fuentes de fertilizantes minerales y organominerales de la formulación, 14-04-08. En las plantas se evaluaron características agronómicas cada quince días (30, 45, 65, 75 días después de la emergencia), altura de la planta, diámetro del tallo, número de hojas, lectura de SPAD y área foliar. La dosis de $600 \mathrm{~kg} \mathrm{ha}^{-1} \mathrm{de} \mathrm{la}$ formulación 04-14-08 proporciona el mejor desarrollo del diámetro del tallo y altura de la planta. La fuente organomineral proporciona una mayor altura de la planta de maíz, número de hojas y área foliar. El fertilizante organomineral es eficaz para asegurar el crecimiento y desarrollo del maíz.

Palabras clave: Zea mays; Macronutrientes; Fertilizantes; Nutrición vegetal.

\section{Introdução}

O Brasil é o terceiro maior produtor mundial de milho (Zea mays L.). No entanto, o rendimento médio brasileiro (média de 5,63 $\mathrm{Mg} \mathrm{ha}^{-1}$ ) ainda é baixo em comparação com áreas de alto rendimento dos EUA (média de 10,84 Mg ha-1) e Europa (média de 8,39 $\mathrm{Mg} \mathrm{ha}^{-1}$ ) (EUROSTAT, 2020; USDA, 2020; CONAB, 2020). A área do Cerrado Brasileiro compreende cerca de 204,7 milhões de hectares, equivalente a 23,3\% das terras do país (IBGE, 2019), sendo a principal área de expansão das lavouras no Brasil. O milho está entre as culturas de grãos cultivadas mais relevantes e utilizadas para consumo humano e animal (Foster et al., 2016).

A fertilidade do solo é apontada como um dos principais fatores interligado à baixa produtividade das áreas destinadas para a produção de grãos, e não está relacionado somente aos baixos teores de nutrientes presentes nos solos, mas também, ao uso impróprio de adubações, principalmente com macronutrientes (Valderrama et al., 2011).

Os fertilizantes podem ser mineral, orgânico ou organomineral, cujo último consiste numa mistura dos anteriores. Os fertilizantes minerais são constituídos de composto inorgânicos e são os mais usados na agricultura, pelo alto conteúdo de 
nutrientes disponíveis. Fertilizantes orgânicos são compostos de material orgânico de origem animal ou vegetal e podem ser oriundos de matérias-primas industriais; urbana ou rural (Camargo, 2012).

O Brasil se destaca como um dos maiores produtores de aves, cujo país no ano de 2017, produziu aproximadamente 13 milhões de toneladas de carne de frango, sendo o estado de Goiás responsável por 7,15\% desse total e 4,3\% das exportações (ABPA, 2018). Esses resíduos apresentam consideráveis quantidades de matéria orgânica e nutrientes, especialmente N, P e K, que podem ser reaproveitados pelas plantas; no entanto, tem se a necessidade de se fornecerem alternativas para a destinação adequada da cama de frango, de forma que, além de minimizar os riscos de poluição ambiental, a mesma possa ser aproveitada como fonte alternativa de renda e/ou na redução dos custos de produção dentro da propriedade.

Os fertilizantes organominerais são constituídos de resíduos organicos enriquecidos com fertilizante mineral. Uma das características do fertilizante orgânico é a baixa concentração de N, P e K e alta concentração de material orgânico. Porém, ao adicionar o fertilizante mineral de forma complementar ao resíduo orgânico, compõe-se os organominerais. O uso de fertilizante organomineral corresponde a uma solução tecnológica, tanto sob o ponto de vista ambiental, como agronômico, pois combinam fertilizantes minerais (matéria prima minerais) e material orgânico (resíduos orgânicos). Desta forma, o uso dos fertilizantes organominerais pode ser uma alternativa inovadora na produção de grãos, pois podem diminuir os custos de produção, otimizar recursos naturais que não poderiam ser descartados e ainda gerar economia (Silva et al., 2006).

Uma das vantagens relacionando aos fertilizantes organominerais em relação aos fertilizantes minerais é a utilização de resíduos como matéria prima, passivos ambientais oriundos de outros processos produtivos. Atualmente, evidencia-se a necessidade de reaproveitar todos os resíduos sólidos agregando valor. A proximidade entre a geração de resíduos, granjas de avícolas e suínas com a produção de grãos, fez-se outro ponto favorável à utilização desses resíduos como fertilizante. Essa proximidade proporciona a redução dos custos logísticos, e favorece a instalação de indústrias locais e regionais no processamento dos fertilizantes organominerais (Benites et al., 2010; Borges et al., 2012).

A aplicação contínua de compostos orgânicos, pode proporcionar o efeito cumulativo de nutrientes no solo, havendo a possibilidade de diminuição nas taxas de aplicações necessárias para alcançar os máximos rendimentos (Nunes et al., 2015; Borges et al., 2012). Em trabalho realizado por Pereira et. al. (2012), com a cultura do milho em função do efeito residual da adubação organomineral em cultivo de segundo ano consecutivo, verificaram que a adubação organomineral promoveu interações benéficas como melhoria na estrutura química e física do solo, resultando no fornecimento de nutrientes as plantas de milho.

Estudo com adubação orgânica é de expressiva importância para o crescimento e desenvolvimento das culturas, como milho por exemplo, a fim de se reaproveitar o potencial desses materiais como fertilizantes, contribuindo, ainda, para a ciclagem de nutrientes, melhoria e conservação do solo (Pauletti et al., 2008; Lima; Menezes, 2014; Geremias et al., 2015). Os fertilizantes organominerais podem aumentar a biodisponibilidade do fósforo devido à competição por sítios de adsorção de fósforo pelos ácidos orgânicos gerados pela mineralização da matéria orgânica (Fernandes et al., 2015).

Neste aspecto, o uso de resíduos orgânicos para a produção de fertilizantes organominerais torna-se uma alternativa sustentável e economicamente viável para a fertilização do solo, e pode amenizar o passivo ambiental das atividades como por exemplo avicultura e suinocultura, geradoras de grande quantidade de resíduos (Junek et al., 2014).

O manejo inadequado e desproporcionado de fertilizantes minerais conduz à crescente degradação do solo, e contribui para a redução da fertilidade, provoca acidez, reduz a biodiversidade do solo, além da emissão de gases do efeito estufa, sendo um dos principais fatores que afetam os solos tropicais (Kotschi, 2013).

Considerando-se que a produção da cultura do milho está estreitamente relacionada com a escolha de fontes e manejo da adubação, que tem impacto direto na nutrição da planta, que constitui fator essencial para atingir altas produtividades. Além disso, que os macronutrientes NPK são os nutrientes absorvidos em maior quantidade e essencial para o crescimento e 
desenvolvimento da planta, portanto, é de grande importância o estudo de fontes alternativas, no intuito de disponibilizar nutrientes para a manutenção da fertilidade do solo e nutrição da planta.

A adubação organomineral vem sendo uma nova alternativa para reduzir os custos de produção da cultura do milho, possibilitando o aumento da produtividade, sem afetar os recursos naturais, gerando, com isso, melhor sustentabilidade (Hoffmann et al., 2015). Ao contrário da adubação mineral que apresenta uma dinâmica diferenciada no solo, cujos elementos essências N, P e K, quando fornecidos pela adubação mineral deixa pequeno residual, ao contrario da adubação organomineral (Montenegro et al., 2013).

Os nutrientes proporcionam a maior contribuição nos componentes do rendimento e na produtividade do milho, influenciando diversas característica do crescimento e desenvolvimento (Mota et al., 2015). O objetivo deste estudo foi avaliar o efeito de doses de adubação e fontes de formulado mineral e organomineral NPK no crescimento, desenvolvimento e leitura de SPAD de plantas de milho.

\section{Metodologia}

O estudo foi conduzido no Instituto Federal de Educação, Ciência e Tecnologia Goiano, Campus Rio Verde, GO, situado na latitude $17^{\circ} 48^{\prime} 19,1^{\prime \prime S}$ e longitude 5054'15,8"W, com altitude média de 720 metros. O clima da região é classificado conforme Köppen (Castro Neto, 1982), como Aw (tropical), com chuva nos meses de outubro a maio, e com seca de junho a setembro. A temperatura média anual varia de 20 a $35{ }^{\circ} \mathrm{C}$ e as precipitações pluviométricas variam de 1.500 a $1.800 \mathrm{~mm}$ anuais. A condução do experimento deu-se em período de temperaturas, intensidade e distribuição de chuvas favoráveis ao cultivo do milho, cujas precipitações pluviais registradas durante a condução do experimento encontram-se na Figura 1.

Figura 1. Precipitação pluviométrica e temperaturas registradas durante a condução do experimento, Rio Verde, Goiás, Safra 2016/17.

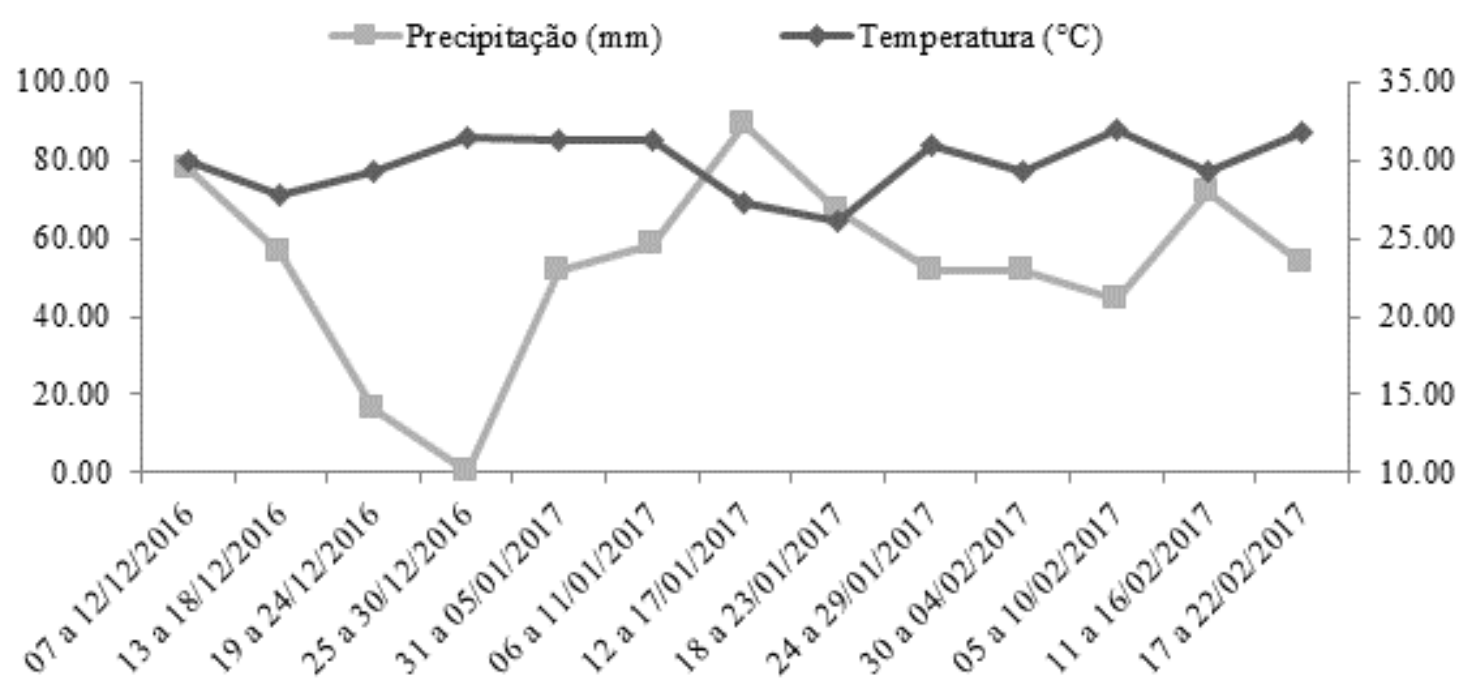

Fonte: Dados da Rede do INMET.

O cultivo do milho foi realizado e vasos plástico, dispostos a céu aberto, contendo $25 \mathrm{~L}$ de solo, coletado na camada de 0-0,20 m de um Latossolo Vermelho distrófico (Santos et al., 2018).

Antes da semeadura do milho, foram coletadas amostras de solo para análises químicas, que foram analisadas conforme metodologias descritas em Raij et al. (2001), em que foram obtidos os seguintes atributos químicos: $\mathrm{pH}\left(\mathrm{CaCl}_{2}\right): 5,2$; P (resina): 11 mg dm${ }^{-3} ; \mathrm{K}: 1,1 \mathrm{mmolc} \mathrm{dm}^{-3} ; \mathrm{Ca}: 19 \mathrm{mmolc} \mathrm{dm}^{-3} ; \mathrm{Mg}: 14 \mathrm{mmolc} \mathrm{dm}^{-3} ; \mathrm{S}: 6 \mathrm{mg} \mathrm{dm}^{3} ; \mathrm{Al}: 2$ mmolc dm${ }^{-3} ; \mathrm{SB}: 34,1$ 
mmolc dm${ }^{-3}$; CTC: $62,1 \mathrm{mmolc} \mathrm{dm}^{-3} ;$ M.O: $44 \mathrm{~g} \mathrm{~kg}^{-1} ; \mathrm{V}: 60 \%$, teor de argila: $42 \%$.

$\mathrm{O}$ delineamento experimental utilizado foi o de blocos ao acaso, analisado em esquema fatorial $5 \times 2$, com quatro repetições, constituídos por cinco doses de formulado 04-14-08 $\left(0,150,300,450,600 \mathrm{~kg} \mathrm{ha}^{-1}\right.$ do produto, equivalente para vaso) e duas fontes de fertilizantes mineral e organomineral da formulação NPK 04-14-08.

A composição do fertilizante organomineral, proveniente da mistura da matéria-prima de cama de frango com fontes minerais, de acordo com a composição química do formulado NPK 04-14-08, encontra-se na Tabela 1.

Tabela 1. Composição do formulado 04-14-08 da Minorgan em organomineral.

\begin{tabular}{lcccccccccc}
\hline $\mathrm{N}$ & $\mathrm{P}$ & $\mathrm{K}$ & $\mathrm{Ca}$ & $\mathrm{Mg}$ & $\mathrm{S}$ & $\mathrm{Fe}$ & $\mathrm{Cu}$ & $\mathrm{Zn}$ & $\mathrm{Mn}$ & $\mathrm{M} . \mathrm{O}$ \\
\hline \multirow{2}{*}{04} & 14 & 08 & 7,6 & 0,44 & 2,12 & 0,13 & 121,8 & 278,4 & 135,7 & 32 \\
\hline
\end{tabular}

Fonte: Autores.

Para o cálculo das quantidades de formulados NPK mineral e organomineral, foram consideradas as respectivas doses e a população de 70.000 plantas de milho por hectare (Cantarella et al., 1997). Cada unidade experimental foi constituída por um vaso plástico contendo $25 \mathrm{~L}$ de solo com duas plantas de milho, totalizando 40 unidades experimentais, com mais 20 vasos referentes à bordadura.

O híbrido de milho cultivado foi o $\mathrm{P} 3844 \mathrm{H}$, que apresenta alto potencial produtivo e recomendado para cultivo no verão, cuja semeadura foi realizada manualmente, em 5/12/2016, distribuindo-se quatro sementes por vasos. Aos sete dias após a emergência (DAE), procedeu-se o desbaste, deixando duas plantas por vaso.

$\mathrm{Na}$ adubação de semeadura, foram aplicadas cinco doses dos formulados mineral e organomineral, de acordo com os respectivos tratamentos. Posteriormente, foram realizadas duas adubações nitrogenadas em coberturas, na dose total de $100 \mathrm{~kg}$ ha $^{-1}$, ou seja 3,10 $\mathrm{g} \mathrm{vaso}^{-1}$, compreendendo: 50\% aos 20 DAE e 50\% aos 40 DAE. Nos tratamentos com a fonte mineral, usouse a ureia $(45 \%$ de $\mathrm{N})$ e para fonte organomineral usou-se super $\mathrm{N}$ organomineral $(45 \%$ de $\mathrm{N})$, cuja aplicação do adubo foi ao entorno das plantas no vaso, seguida de irrigação.

As variáveis avaliadas foram: diâmetro do colmo $(\mathrm{mm})$ - medição a cada quinze dias do diâmetro do colmo, na altura de $1 \mathrm{~cm}$ do solo, com auxílio de um paquímetro digital; altura da planta $(\mathrm{cm})$ - medição da altura das plantas, a cada quinze dias, a partir do colo da planta até a curvatura da última folha com régua graduada em cm; número de folhas - contagem cada quinze dias o número de folhas totalmente expandidas; Teor de clorofila - realizou a estimativa do teor de clorofila indiretamente por meio de leituras de unidades SPAD (Soil Plant Analysis Development) com o aparelho clorofilômetro SPAD-502® (Minolta, 1989), no último par de folhas completamente desenvolvidas, utilizou-se a média de duas leituras por folha, que foram realizadas na parte mediana do limbo; Área foliar $\left(\mathrm{cm}^{2}\right)$ - medição do comprimento e largura da folha, com a utilização da equação $\mathrm{C} \mathrm{x} \mathrm{L*0,75,} \mathrm{em} \mathrm{que} \mathrm{c=} \mathrm{comprimento} \mathrm{da} \mathrm{folha,} \mathrm{L}=$ largura da folha (Francis et al., 1969).

Os dados foram submetidos à análise de variância, e, quando detectados efeitos significativos pelo teste $\mathrm{F}$, a $5 \%$ de probabilidade, foram ajustadas equações de regressão para as doses e comparação de médias pelo teste de Tukey, a $5 \%$ de probabilidade, utilizando o programa estatístico SISVAR (Ferreira, 2011).

\section{Resultados e Discussão}

Os resumos das análises de variância para as variáveis do milho de acordo com o tempo de avaliação estão apresentados na Tabela 1, 2 e 3. Para diâmetro de colmo (DC), houve efeito significativo (p>0,01) em função de doses de NPK. Já para a altura de planta (Al) e área foliar (AF), houve efeito significativo ( $>0,01)$ de doses e fontes de NPK mineral e 
organomineral. Enquanto para número de folhas (NF) e Leitura SPAD houve efeito significativo (p>0,01) da interação entre doses e fontes.

Tabela 2. Resumo da análise da análise de variância para as variáveis diâmetro de colmo e altura de planta de milho em função de fontes e doses de formulados mineral e organomineral NPK, avaliadas aos 30, 45, 65 e 75 dias após a emergência (DAE).

\begin{tabular}{|c|c|c|c|c|c|c|c|c|c|}
\hline \multirow{3}{*}{ FV } & \multirow{3}{*}{ GL } & \multicolumn{8}{|c|}{ Quadrado Médio } \\
\hline & & \multicolumn{4}{|c|}{-Diâmetro do Colmo- } & \multicolumn{4}{|c|}{-Altura de Planta- } \\
\hline & & 30 DAE & $45 \mathrm{DAE}$ & $65 \mathrm{DAE}$ & 75 DAE & $30 \mathrm{DAE}$ & $45 \mathrm{DAE}$ & $65 \mathrm{DAE}$ & $75 \mathrm{DAE}$ \\
\hline Fonte & 1 & $5,69^{\mathrm{ns}}$ & $0,10^{\mathrm{ns}}$ & $2,43^{\mathrm{ns}}$ & $0,003^{\mathrm{ns}}$ & $19,60^{\mathrm{ns}}$ & $3508^{* *}$ & $7240,78^{\mathrm{ns}}$ & $68,90^{\mathrm{ns}}$ \\
\hline Doses & 4 & $330^{* *}$ & $224,55^{* *}$ & $128,92^{* *}$ & $105,56^{* *}$ & $977,05^{* *}$ & $24206^{* *}$ & $254,77^{* *}$ & $3041,39^{* *}$ \\
\hline Fonte $\mathrm{x}$ Doses & 4 & $3,83^{\mathrm{ns}}$ & $1,28^{\mathrm{ns}}$ & $1,30^{\mathrm{ns}}$ & $40,23^{\text {ns }}$ & $3,22^{\mathrm{ns}}$ & $310^{\mathrm{ns}}$ & $45,68^{\text {ns }}$ & $40,23^{\text {ns }}$ \\
\hline Bloco & 3 & 7,27 & 3,17 & 6,30 & $133,77^{\mathrm{ns}}$ & 38,54 & 421 & 41,23 & 133,77 \\
\hline Resíduo & 27 & 3,06 & 3,04 & 2,18 & 74,32 & 10,33 & 278 & 106,68 & 74,32 \\
\hline $\mathrm{CV}(\%)$ & & 9,04 & 8,69 & 7,42 & 10,34 & 9,38 & 23,83 & 13,35 & 10,34 \\
\hline
\end{tabular}

ns não significativo, ${ }^{* *}$ significativo a $1 \% \mathrm{e}^{*}$ significativo a $5 \%$ de probabilidade segundo teste $\mathrm{F}$. GL - Grau de Liberdade e CV Coeficiente de Variação. Fonte: Autores.

Tabela 3. Resumo da análise de variância para as variáveis número de folhas e área foliar de milho em função de fontes e doses de formulados mineral e organomineral NPK, avaliadas aos 30, 45, 65 e 75 dias após a emergência (DAE).

\begin{tabular}{|c|c|c|c|c|c|c|c|c|c|}
\hline \multirow{3}{*}{ FV } & \multirow{3}{*}{ GL } & \multicolumn{8}{|c|}{ Quadrado Médio } \\
\hline & & \multicolumn{4}{|c|}{ —Número de Folhas } & \multicolumn{4}{|c|}{ Área Foliar- } \\
\hline & & $30 \mathrm{DAE}$ & $45 \mathrm{DAE}$ & $65 \mathrm{DAE}$ & $75 \mathrm{DAE}$ & $30 \mathrm{DAE}$ & $45 \mathrm{DAE}$ & $65 \mathrm{DAE}$ & 75 DAE \\
\hline Fonte & 1 & $0,90^{\mathrm{ns}}$ & $17,10^{* *}$ & $16,57^{\mathrm{ns}}$ & $0,50^{\mathrm{ns}}$ & $103,64^{\mathrm{ns}}$ & $122995^{* *}$ & $59251,60^{* *}$ & $15102,16^{\mathrm{ns}}$ \\
\hline Doses & 4 & $6,92^{* *}$ & $12,10^{\mathrm{ns}}$ & $0,30^{* *}$ & $5,67^{* * *}$ & $127639^{* * *}$ & $22318^{* *}$ & $181718,82^{* *}$ & $198995,44^{* *}$ \\
\hline $\begin{array}{ll}\text { Fonte } & \mathrm{x} \\
\text { Doses } & \end{array}$ & 4 & $0,25^{\mathrm{ns}}$ & $1,77^{*}$ & $0,32^{\mathrm{ns}}$ & $1,05^{\mathrm{ns}}$ & $6026^{\mathrm{ns}}$ & $5984^{\mathrm{ns}}$ & $4457,20^{\mathrm{ns}}$ & $5075,85^{\mathrm{ns}}$ \\
\hline Bloco & 3 & 0,63 & 1,09 & 0,32 & 0,27 & 5144 & 1165 & 8079,09 & 2114,03 \\
\hline Resíduo & 27 & 0,33 & 0,44 & 1,21 & 1,04 & 3018 & 2268 & 5096,26 & 4800,10 \\
\hline CV (\%) & & 6,41 & 8,34 & 12,31 & 10,40 & 12,12 & 10,8 & 14,03 & 13,86 \\
\hline
\end{tabular}

${ }^{\text {ns }}$ não significativo e ${ }^{* *}$ significativo a $1 \% \mathrm{e}^{*}$ significativo a $5 \%$ de probabilidade segundo teste F. GL - Grau de Liberdade e CV Coeficiente de Variação. Fonte: Autores. 
Tabela 4. Resumo da análise da análise de variância para a variável leitura SPAD em folhas de plantas de milho, em função de fontes e doses de formulados mineral e organomineral NPK, avaliadas aos 30, 45, 65 e 75 dias após a emergência (DAE).

\begin{tabular}{|c|c|c|c|c|c|}
\hline \multirow{3}{*}{ FV } & \multirow{3}{*}{ GL } & \multicolumn{4}{|c|}{ Quadrado Médio } \\
\hline & & \multicolumn{4}{|c|}{ SPAD } \\
\hline & & $30 \mathrm{DAE}$ & $45 \mathrm{DAE}$ & $65 \mathrm{DAE}$ & $75 \mathrm{DAE}$ \\
\hline Fonte & 1 & $0,95^{\mathrm{ns}}$ & $21,72^{\mathrm{ns}}$ & $12,33^{* *}$ & $348,40^{\text {*** }}$ \\
\hline Doses & 4 & $159,62^{* *}$ & $5,97^{\mathrm{ns}}$ & $85,15^{\mathrm{ns}}$ & $204,75^{* *}$ \\
\hline Fonte x Doses & 4 & $5,51^{\mathrm{ns}}$ & $5,55^{\mathrm{ns}}$ & $24,80^{* *}$ & $18,23^{\mathrm{ns}}$ \\
\hline Bloco & 3 & 3,44 & 2,57 & 2,55 & 22,59 \\
\hline Resíduo & 27 & 7,11 & 7,39 & 5,72 & 25,96 \\
\hline $\mathrm{CV}(\%)$ & & 7,14 & 8,5 & 8,45 & 16,61 \\
\hline
\end{tabular}

${ }^{\text {ns }}$ não significativo e ${ }^{* *}$ significativo a $1 \%$ de probabilidade segundo teste F. GL - Grau de Liberdade e CV - Coeficiente de Variação. Fonte: Autores.

O diâmetro do colmo apresentou diferença significativa entre as doses e os períodos de avaliações de 30, 45, 65 e 75 DAE, cujos dados adequaram-se ao modelo quadrático, com $\mathrm{R}^{2}$ acima de $96 \%$, exceto aos 75 DAE, em que os dados ajustaram ao modelo linear Figura 2A. As doses de formulado NPK nos períodos avaliados elevaram o DC do milho até a dose $600 \mathrm{~kg}$ $\mathrm{ha}^{-1}$. 
Figura 2. Diâmetro do colmo (A) e altura da planta de milho (B e C) em função das doses de formulados NPK 04-14-08 mineral e organomineral.
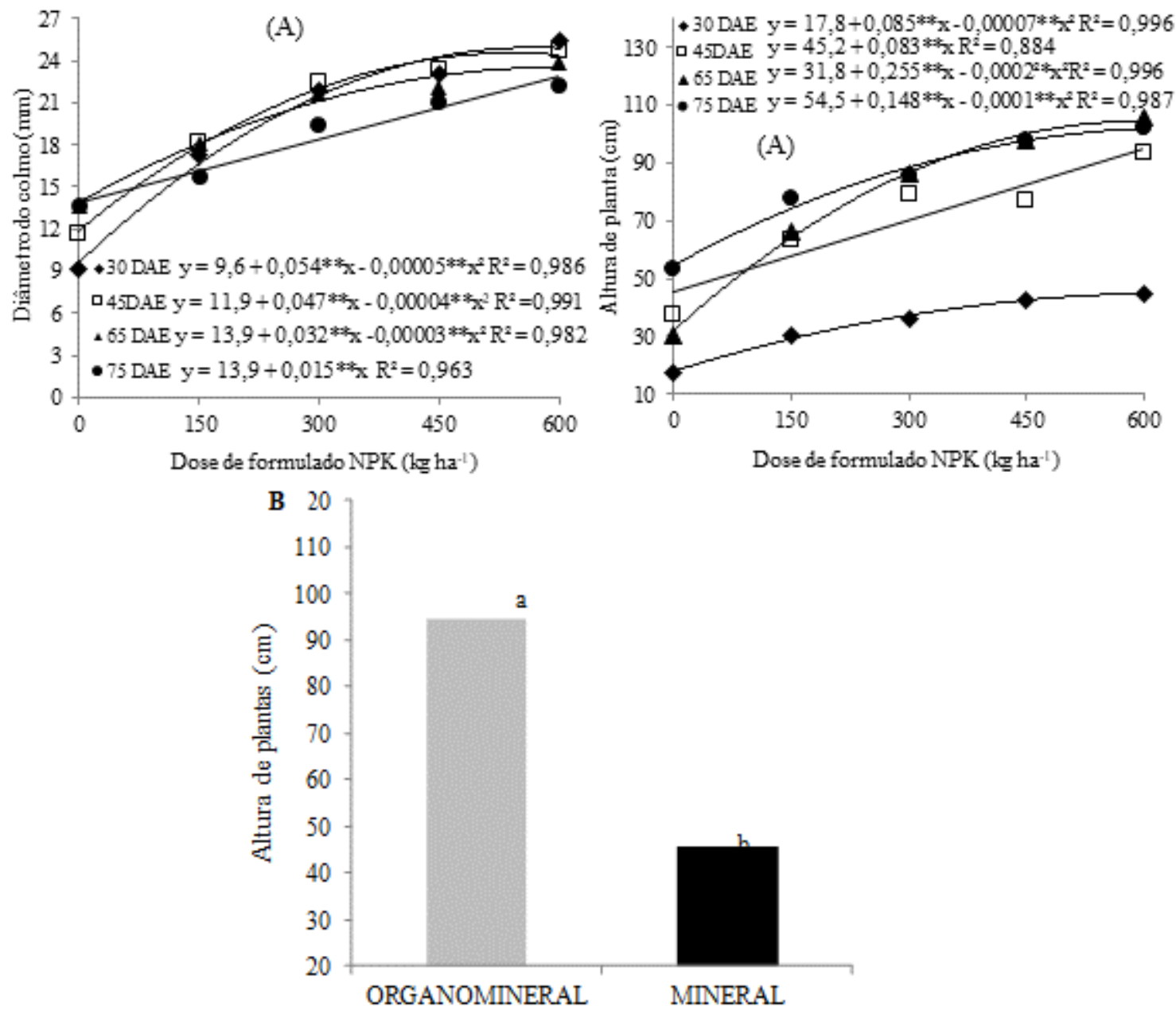

Fontes do formulado NPK 04-14-08

Fonte: Autores.

O diâmetro do colmo (DC) em função das doses e os períodos de avaliações, para a avaliação realizada aos 75 DAE adequaram-se ao modelo linear, com $\mathrm{R}^{2}$ acima de $96 \%$ (Figura 2A). As doses de formulado para avaliação aos 75 DAE elevaram o DC do milho até a dose $600 \mathrm{~kg} \mathrm{ha}^{-1}$, sendo que com a aplicação dessa dose do formulado NPK foi atingida o maior DC, de aproximadamente $25 \mathrm{~mm}$. O maior DC verificado na dose $600 \mathrm{~kg} \mathrm{ha}^{-1}$ foi superior 39, 29, 19 e $9 \%$ maiores do que DC observada nas doses do formulado de $0,150,300$ e $450 \mathrm{~kg} \mathrm{ha}^{-1}$, respectivamente. Goes et al. (2013) observaram que as doses crescentes de adubação nitrogenada aumentaram a altura de plantas, altura de inserção da primeira espiga, assim como o diâmetro do colmo do milho.

O diâmetro do colmo das plantas não apresentou diferença significativa entre as fontes organomineral e mineral nas doses de $0,150,300,450$ e $600 \mathrm{~kg} \mathrm{ha}^{-1}$. Assim, tanto o fertilizante mineral como o organomineral, foram semelhantes ao desenvolvimento para o diâmetro do colmo, quando comparados com a testemunha como mostrado na Tabela 2. Assim como os resultados encontrados por outros estudos, a exemplo do observado por Pereira Júnior et al. (2012), que não obtiveram resultados significativos para diâmetro de colmo em milho; porém, os autores verificaram que a adubação com cama de frango proporcionou resposta superior comparada à adubação com resíduos de suínos e ovinos. DAGA et al. (2009) encontraram diferença entre o adubo mineral e a cama de frango, cuja adubação mineral proporcionou aumentos na altura de inserção da 
espiga e no diâmetro de colmo. Já Rodrigues et al. (2012), avaliando fertilizante mineral 08-20-20 na dose $450 \mathrm{~kg} \mathrm{ha}^{-1}$, obtiveram maior desenvolvimento vegetativo para a altura de planta, altura de inserção de espiga e diâmetro do colmo.

O diâmetro de colmo é uma característica estreitamente relacionada à produtividade, por ser um órgão de reserva para as plantas, assim, correlaciona diretamente com o desempenho dos grãos (Cruz et al., 2008).

A altura de planta (AP) de milho em função das doses do formulado NPK para os períodos de avaliação encontra-se na Figura 2B. Observou-se que os dados de altura de planta nos períodos de 30, 45, 65 e 75 DAE, adequaram-se ao modelo quadrático, com R $\mathrm{R}^{2}$ acima de $96 \%$, exceto aos $45 \mathrm{DAE}$, e elevaram a altura de plantas de milho até a dose $600 \mathrm{~kg} \mathrm{ha}^{-1}$.

A altura de plantas em função das doses e períodos de avaliações, para a avaliação aos 75 DAE adequou-se ao modelo quadrático, com $\mathrm{R}^{2}$ de $98 \%$ (Figura 2B). As doses de formulado para avaliação aos 75 DAE elevaram o AP do milho até a dose $600 \mathrm{~kg} \mathrm{ha}^{-1}$. Com aplicação dessa dose do formulado foi atingida a máxima AP, de aproximadamente $102 \mathrm{~cm}$. A AP verificada na dose $600 \mathrm{~kg} \mathrm{ha}^{-1}$ foi superior 64, 48, 32 e $16 \%$ maiores do que AP observada nas doses do formulado de 0, 150, 300 e 450 $\mathrm{kg} \mathrm{ha}^{-1}$, respectivamente. Consequentemente, de acordo com a equação de regressão obteve o acréscimo de 16,16\%, para cada aumento de $150 \mathrm{~kg} \mathrm{ha}^{-1}$ do formulado 04-14-08 mineral e organomineral.

Para os valores de altura de planta de milho, observa-se que para a testemunha, nos períodos avaliados, apresentou crescimento lento da planta, justificado pela menor quantidade de fornecimento dos nutrientes necessários às plantas (Figura 2B). Silva et al. (2011), ao avaliarem o efeito de doses de cama de frango sobre o desenvolvimento inicial de milho, verificaram que adição de 10,5 gramas de cama de frango para cada quilo de solo, no tempo de incubação de 30 dias, promoveram maiores altura de plantas, diâmetro de colmo e biomassa seca. A adubação orgânica por manter o solo superficialmente mais úmido, favorece as condições químicas e físicas, além fornecer $\mathrm{N}$ como nutriente (Souza, 1998).

Houve diferença significativa na altura de planta entre as fontes mineral e organomineral, na avaliação aos 45 DAE, cuja fonte com organomineral foi $51 \%$ maior do que a fonte mineral (Figura 2C). Tal fato corrobora com os resultados encontrados por Carvalho et al. (2015), ao avaliaram os efeitos de fertilizantes minerais 4-30-10, organomineral e cama de frango sobre o crescimento inicial do milho aos 30 e 45 DAE. Os autores observam que, quando comparadas as alturas de plantas, o fertilizante organomineral proporcionou melhor desenvolvimento, mas não sendo superior estatisticamente aos demais adubos. Mata et al. (2010), ao avaliarem adubação orgânica (esterco bovino) em milho a campo, verificaram na dose de $40 \mathrm{t} \mathrm{ha}^{-1}$, aos $56 \mathrm{DAE}$, valores de altura de planta de 1,63 $\mathrm{m}$. Como os resultados semelhantes encontrados por Gomes et al. (2005), Carvalho et al. (2015) e Vale et al. (2015), também observaram que a adubação orgânica proporcionou maiores valores de altura de planta de milho, quando comparados à adubação mineral.

O número de folhas $(\mathrm{NF})$ da planta de milho foi significativo a ( $>00,01)$ em função das doses de formulado somente para os períodos de 30, 65 e 75 DAE (Figura 3A). O número de folhas aos 30 DAE adequou se ao modelo linear, enquanto o NF em função das doses de formulado para o período de avaliação aos 65 e 75 DAE, adequaram-se ao modelo quadrático, com $\mathrm{R}^{2}$ de 94 e $81 \%$, respectivamente. Para os mesmos, com aplicação da dose $300 \mathrm{~kg} \mathrm{ha}^{-1}$ do formulado NPK, foi atingida número de folhas máximo de aproximadamente 10 folhas planta ${ }^{-1}$. 
Figura 3. Número de folhas da planta de milho em função das doses de formulados NPK. Interação das doses do formulado NPK 04-14-08 (A) e fontes mineral e organomineral (B) para variável número de folhas da planta de milho.
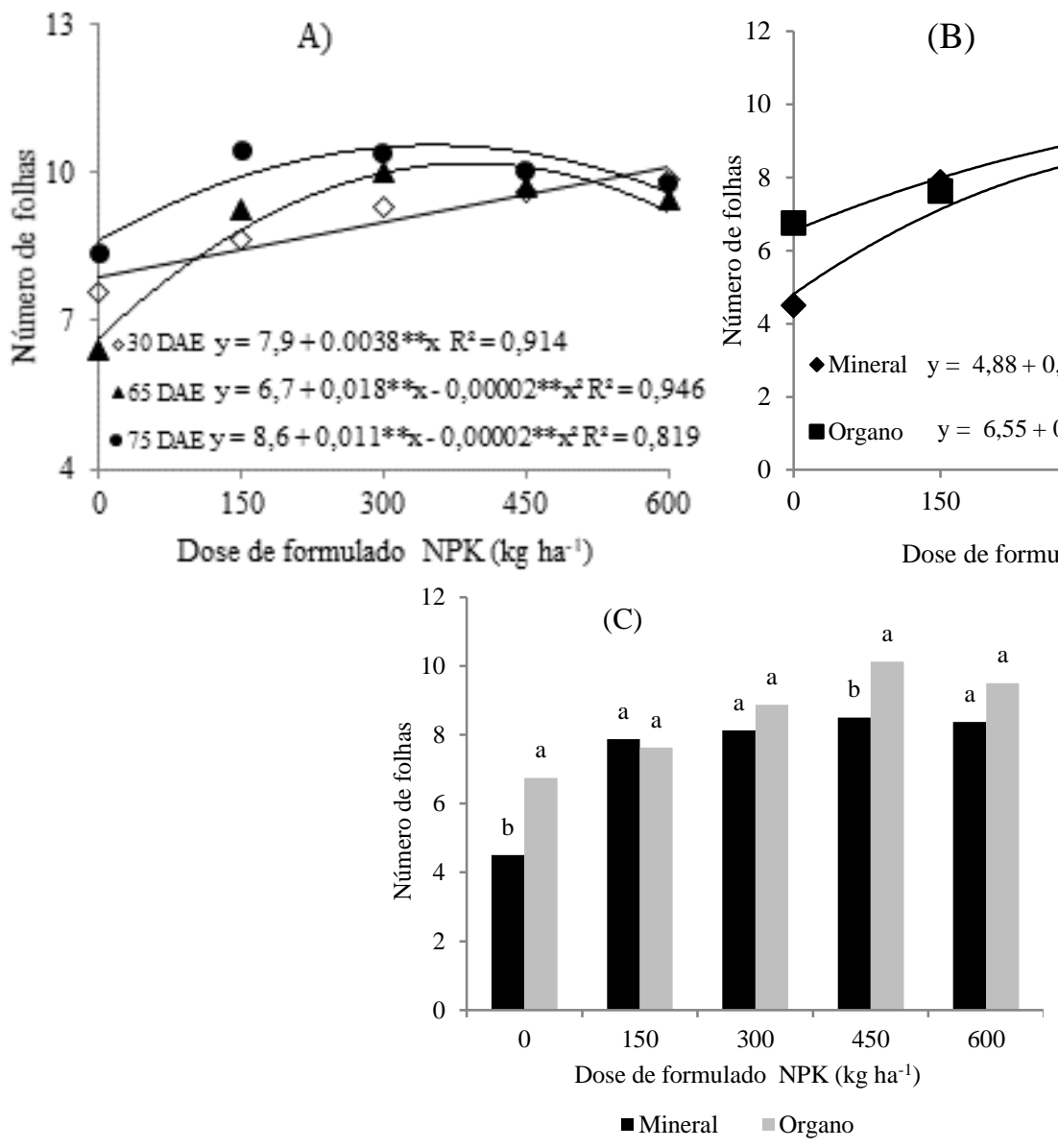

Fonte: Autores.

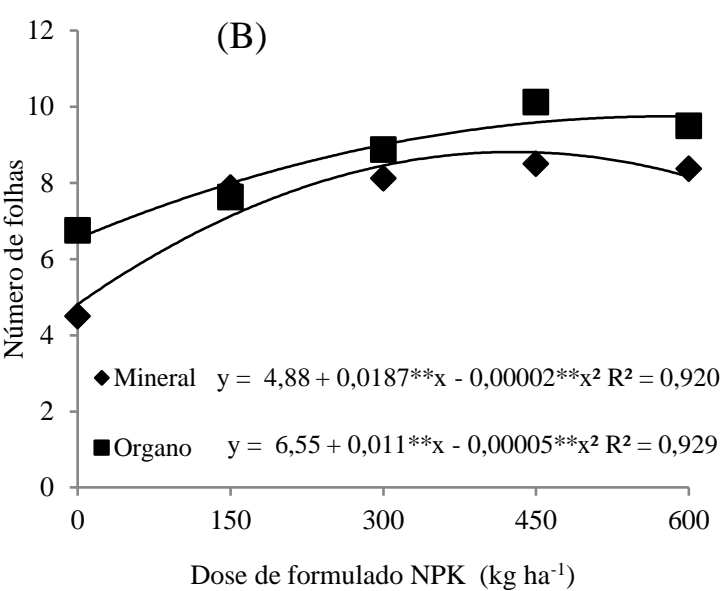

Na Figura 3B e 3C, encontra-se o desdobramento para os fatores doses e fontes, na avaliação realizada aos 45 DAE, para o número de folhas, em função das doses do formulado NPK para organomineral e mineral. As doses de formulado NPK para fonte organomineral adequaram-se ao modelo quadrático, com $\mathrm{R}^{2}$ acima de $92 \%$, em que ocorreu aumento do número de folhas no milho até a dose $600 \mathrm{~kg} \mathrm{ha}^{-1}$ (Figura 5A). Com aplicação dessa dose do formulado NPK, foi atingida o maior número de folhas, de aproximadamente 10 folhas plantas ${ }^{-1}$. O número de folhas máximo verificada na dose $600 \mathrm{~kg} \mathrm{ha}^{-1}$ foi $31,23,15$ e $8 \%$ maior do que observada nas doses do formulado NPK de 0, 150, 300 e $450 \mathrm{~kg} \mathrm{ha}^{-1}$, respectivamente.

O número de folhas em função das doses de formulado NPK para fonte mineral adequou-se ao modelo quadrático, com $\mathrm{R}^{2}$ de $92 \%$ (Figura 5B). As doses de NPK mineral elevaram o número de folhas do milho até a dose estimada de $470 \mathrm{~kg}$ $\mathrm{ha}^{-1}$. Com a aplicação dessa dose do formulado foi atingida o ponto de máximo de aproximadamente 9 folhas planta ${ }^{-1}$. $\mathrm{O}$ número de folhas máximo verificado na dose estimada de $470 \mathrm{~kg} \mathrm{ha}^{-1}$ foi 45,19 e $3 \%$ maior do que observada nas doses do formulado NPK de 0,150 e $300 \mathrm{~kg} \mathrm{ha}^{-1}$, respectivamente.

O NF não apresentou diferença significativa entre as fontes organomineral e mineral nas doses de 150,300 e $600 \mathrm{~kg}$ $\mathrm{ha}^{-1}$ (Figura 3B). As doses de 0 e $450 \mathrm{~kg} \mathrm{ha}^{-1}$ apresentaram diferenças significativas entre as fontes mineral e organomineral, cuja fonte organomineral foi $16 \%$ maior do que a fonte mineral, na dose de $450 \mathrm{~kg} \mathrm{ha}^{-1}$, respectivamente. Na dose 0 , isto é, sem aplicação de NPK na semeadura, houve diferença para as fontes, tal fato é justificado pela adubação de cobertura, em que foram aplicadas de acordo com as fontes, ou seja, fonte de $\mathrm{N}$ mineral (ureia) nos tratamentos que receberam NPK mineral na semeadura e $\mathrm{N}$ (super $\mathrm{N}$ ) organomineral nos tratamentos que receberam organomineral na semeadura. 
Avaliando a área foliar de acordo com os períodos, dias após emergência, observa-se que área foliar é dependente do número, do tamanho de folhas e do estágio vegetativo, sendo que a área foliar aumenta até o limite máximo, qual ela permanece ativa, inicia o crescimento em seguida pelo decréscimo em razão da senescência das folhas (Manfron et al., 2003).

A área foliar das plantas de milho em função das doses do formulado NPK para os períodos de avaliação é apresentado na Figura 4. A área foliar em função das doses de formulado NPK para os períodos de 30, 45, 65 e 75 DAE, adequou-se ao modelo quadrático, com R $\mathrm{R}^{2}$ acima de 80\%, e elevaram a área foliar do milho até a dose $600 \mathrm{~kg} \mathrm{ha}^{-1}$ (Figura 4A). Assim, om a aplicação dessa dose do formulado NPK foi atingida a área foliar máxima das plantas, de aproximadamente 587 $\mathrm{cm}^{2}$. Outra característica observada foi que a área foliar no período vegetativo foram superiores em relação ao período de 75 DAE, período reprodutivo, possivelmente pela relação da taxa de crescimento que diferenciam entre os estágios fenológicos. Tal fato, possivelmente pode ser justificado pela adubação orgânica ser importante fonte de nutrientes, especialmente de N, P, $\mathrm{S}$ e micronutrientes, sendo a única forma de armazenamento de $\mathrm{N}$ que não volatiliza no solo (Pires, Junqueira, 2001). 
Figura 4. Área foliar do milho em função das doses de formulados NPK (A), média da área foliar no milho na avaliação aos 45 dias, após a emergência (DAE) (B) e área foliar na avaliação aos 65 DAE, em função das fontes do formulado NPK 04-1408 mineral e organomineral (C).
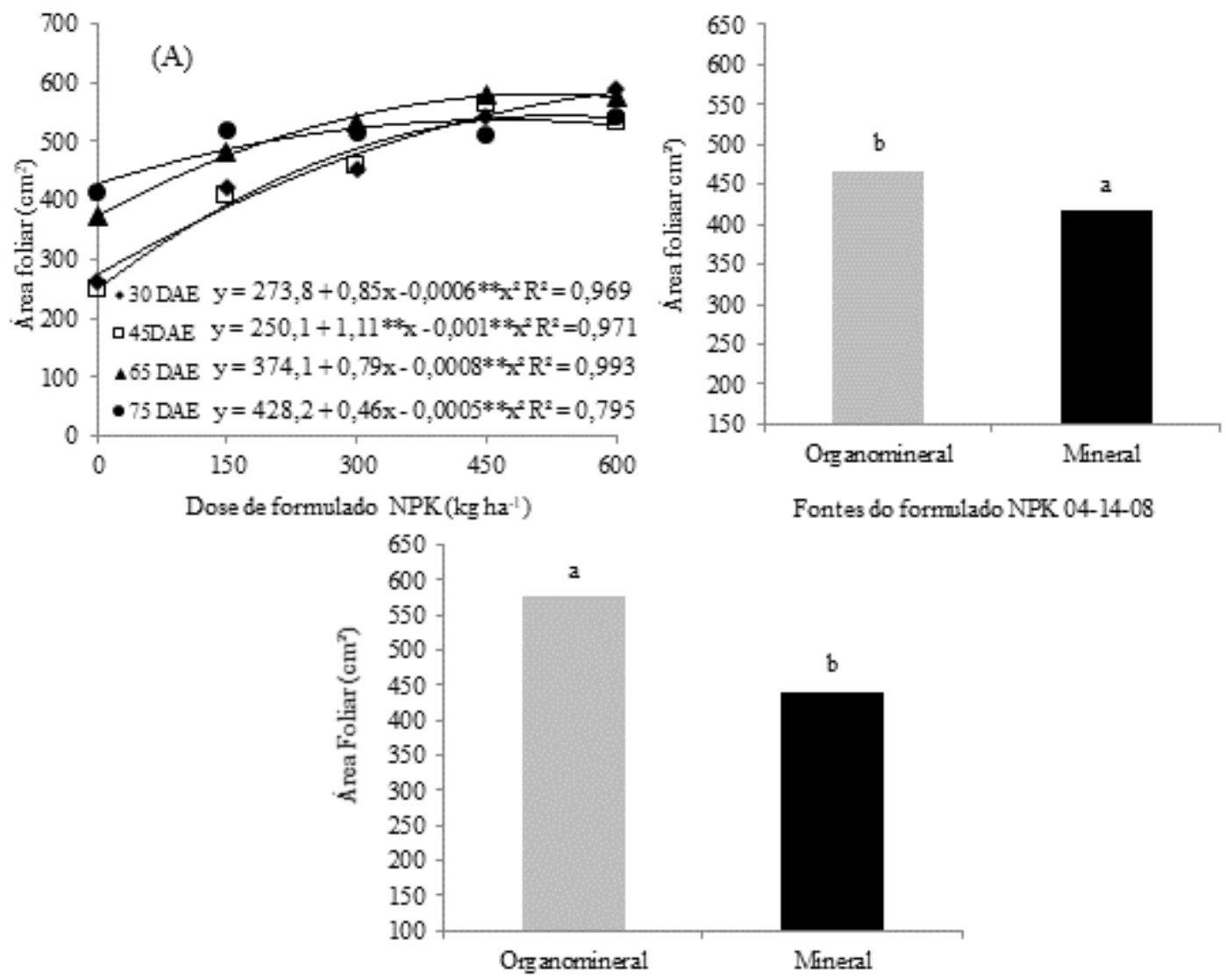

Fontes do formulado NPK 04-14-08

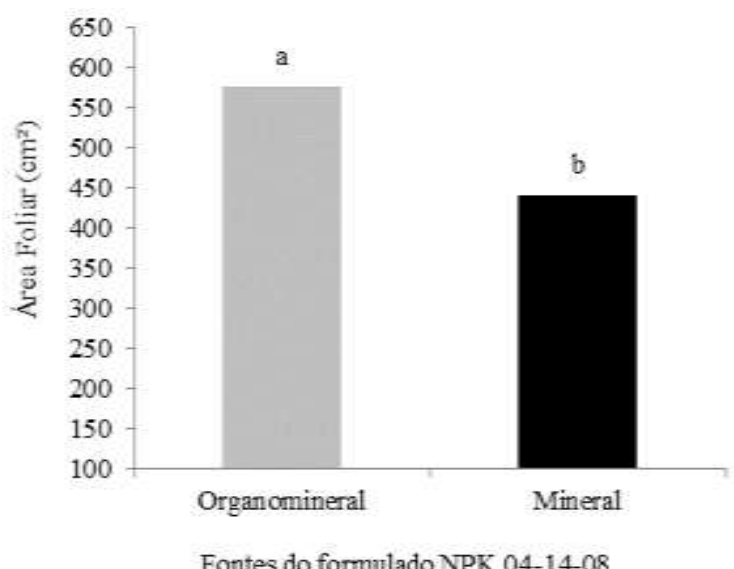

Fonte: Autores.

A área foliar apresentou diferenças significativas entre as fontes mineral e organomineral, na avaliação aos 45 e 65 DAE, cuja fonte organomineral proporcionou valores de 11 e $23 \%$ maiores do que a fonte mineral, respectivamente (Figura 7A; 7B). 
A área foliar representa a capacidade de desenvolvimento do milho, relacionado com a produção, pois folhas bem nutridas têm maior capacidade de assimilar $\mathrm{CO}^{2}$ e sintetizar a fotossíntese, o que resulta em maior acúmulo de biomassa (MATA et al., 2010).

O valor das leituras SPAD nas folhas das plantas de milho em função das doses do formulado NPK para os períodos avaliação é apresentado na Figura 5A. A leitura de SPAD foi significativao a ( $p>0,01)$ em função das doses de formulado NPK somente para os períodos de 30 e 75 DAE.

As doses de formulado NPK para avaliação realizada aos 75 DAE adequaram-se ao modelo quadrático, com R² acima de $96 \%$ (Figura 5A). As doses elevaram o valor da leitura SPAD nas folhas de milho até a dose estimada de $460 \mathrm{~kg} \mathrm{ha}^{-1}$, cuja dose do formulado NPK foi atingida a leitura de valor nas folhas de aproximadamente 34 .

As fontes mineral e organomineral aos 75 DAE, apresentou significância a $1 \%$ de probabilidade, sendo a fonte mineral $17 \%$ superior à fonte organomineral (Figura 5B).

Figura 5. Valores de Leitura SPAD em folhas de planta de milho em função das doses de formulados NPK (A). Médias para leitura de SPAD em folhas de plantas de milho, na avaliação aos 75 dias após emergência, em função das fontes do formulado NPK mineral e organomineral (B). Interação das doses do formulado NPK 04-14-08 versus fontes mineral e organomineral (D) e Fontes versus doses (D) para variável leitura de SPAD em plantas de milho, aos 65 DAE.

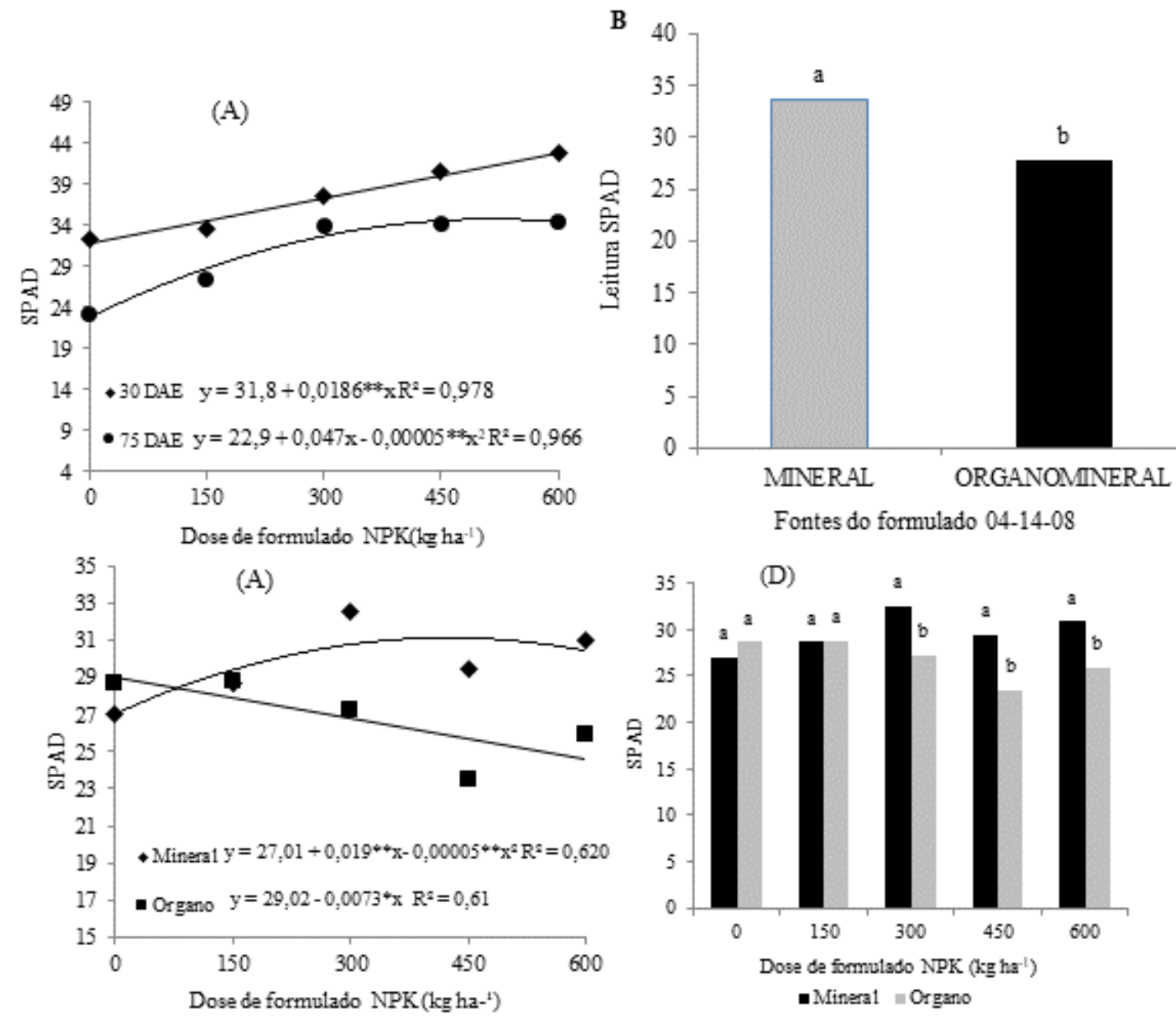

Médias seguidas com letras distintas na coluna, diferem entre si pelo teste de Tukey a 5\%. Fonte: Autores.

Observa-se que os valores de teor de clorofila foram menores na avaliação dos 75 DAE. Nesse período, encontram-se 
no estágio de florescimento e início da formação de grãos de milho, assim ocorre queda do teor de clorofila em razão da menor atividade fotossintética na maturação fisiológica, consequentemente, perda de água nos tecidos vegetais, o que propicia a redução na produção de clorofila (Fiorini et al., 2017).

Ocorreu efeito significativo somente para a avaliação realizada aos 65 DAE. Analisando o desdobramento para os fatores doses e fontes. Verifica-se que as doses de formulado NPK para fonte organomineral adequaram-se ao modelo linear decrescente, com $\mathrm{R}^{2}$ acima de $61 \%$. Consequentemente, de acordo com a equação de regressão obteve decréscimo de $4 \%$, para cada aumento de $150 \mathrm{~kg} \mathrm{ha}^{-1}$ de NPK.

As doses de formulado NPK para fonte mineral adequaram-se ao modelo quadrático, com $\mathrm{R}^{2}$ acima de $62 \%$ (Figura 5C). As doses elevaram o valore da leitura SPAD no milho até a dose $300 \mathrm{~kg} \mathrm{ha}^{-1}$ após, manteve constante as leituras. Com aplicação dessa dose do formulado NPK foi atingida o máximo valor de clorofila nas folhas de aproximadamente 29 planta $^{-1}$, cujos valores foram 15, 12, 8 e 4\% maiores que observado nas doses de 0, 150, 450 e $600 \mathrm{~kg} \mathrm{ha}^{-1}$, respectivamente. Contudo, mesmo com acréscimo das doses do formulado, a planta pode continuar absorvendo o nutriente, denominado de "consumo de luxo"; porém não acontece para clorofila, ao atingir o ponto máximo, a partir as leituras são constantes ou com pequenas variações (Souza et al., 2011).

Para a leitura SPAD, não se observou diferença significativa entre as fontes organomineral e mineral, nas doses de $0 \mathrm{e}$ $150 \mathrm{~kg} \mathrm{ha}^{-1}$ (Figura 5D). Já nas demais doses (300, 450 e $\left.600 \mathrm{~kg} \mathrm{ha}^{-1}\right)$, apresentaram diferenças significativas entre as fontes mineral e organomineral. A fonte mineral proporcionou valores $8,16,12 \%$ maiores do que a fonte organomineral.

De maneira geral, o presente estudo evidencia que o emprego de fontes organominerais consiste em importante opção de fornecimento de nutrientes em cultivos de milho, o que pode reduzir a demanda de fertilizantes minerais e promover a reciclagem de nutrientes e melhorar condições físicas, químicas e biológicas do solo. Isto é importante para o Brasil, uma vez que os custos de produção no país são elevados, cuja maior parte dos fertilizantes minerais é importada e representa uma importante parcela no custo de produção.

\section{Conclusão}

A dose de $600 \mathrm{~kg} \mathrm{ha}^{-1}$ do formulado NPK 04-14-08 proporciona maior diâmetro do colmo e altura de planta de milho. A fonte de organomineral proporciona maior altura de planta de milho, número de folhas e área foliar.

O fertilizante organomineral apresenta potencial para suprir a demanda em nitrogênio, fósforo e potássio do milho, portanto uma importante oportunidade para a reciclagem de nutrientes e destinação mais adequada de resíduos orgânicos associados a fontes minerais.

\section{Agradecimentos}

Os autores agradecem ao Conselho Nacional de Desenvolvimento Científico e Tecnológico (CNPq); à Coordenação de Aperfeiçoamento de Pessoal de Nível Superior (CAPES) e à Fundação de Amparo à Pesquisa do Estado de Goiás (FAPEG), pelo apoio financeiro e estrutural.

\section{Referências}

Benites, V. M., Correa, J. \& Menezes, J. F. S. (2010). Produção de fertilizante organomineral granulado a partir de dejetos de suínos e aves no Brasil. XXIX Reunião Brasileira de Fertilidade do Solo e Nutrição de Plantas. Brasil, 5 p.

Borges, R. E., Menezes, J. F. S., Simon, G. A. \& Benites, V. (2012). Eficiência da adubação com organomineral na produtividade de soja e milho. Gl. Sci Technol, Rio Verde, 08 (01), 177-184. Camargo, M. S. A importância do uso de fertilizantes para o meio ambiente. Pesquisa \& Tecnologia, 9 (2).

Carvalho, A. H. O., Pena, F. E. R., Jaeggi, M. E. P. C., Alvarez, C. R. S. \& Lima, W. L (2015). Desenvolvimento inicial do milho (Zea mays L.) cultivado com fertilizantes minerais e orgânicos. Cadernos de agroecologia. 10 (1). 
Cruz, S. C. S., Pereira, F. R. S., Bicudo, S. J., Albuquerque, A. W., Santos, J. R. \& Machado, C. G. (2008). Nutrição do milho e da Brachiaria decumbens cultivado em consórcio em diferentes preparos do solo. Acta Scientiarum. Agronomy, 30 (05), 733-739.

Daga, J., Richart, A., Nozaki, M. H., Zanetti, T. A. \& Zanetti, R. D. (2009). Desempenho do milho em função da adubação química e orgânica. Synergismus scyentifica. UTFPR, 04 (1), 3p.

Ferreira, D. F. (2011). Sisvar: a computer statistical analysis system. Ciência e Agrotecnologia, 35 (6), 1039-1042.

Fernandes, D. M., Grohskopf, M. A., Gomes, E. R., Ferreira, N. R. \& Büll, L. T. (2015). Fósforo na solução do solo em resposta à aplicação de fertilizantes fluidos mineral e organomineral. Irriga. 1 (1), 14-27.

Fiorini, I. V. A., Pinho, R. G. V., Pereira, H. D., Pires, L. P. M, Fiorini, F. V. A. \& Resende, E. L. (2017). Acúmulo de matéria seca, clorofila e enxofre foliar em milho adubado com diferentes fontes de enxofre. Jornal Bioenergy and Food Science, 4 (1), 1-11.

Geremias, E.V., Segat, J. C., Fachini, I.A., Fonseca, E. O. \& Baretta, D. (2015). Fauna edáfica em pastagem perene sob diferentes fontes de nutrientes. Scientia Agraria, 16 (4), 17-30.

Goes, R. J., Rodrigues, R. A. F., Arf, O. \& Vilela, R. G. (2012). Nitrogênio em cobertura para o milho (Zea mays L.) em sistema plantio direto na safrinha. Revista Brasileira de Milho e Sorgo, 11(2), 169-177.

Gomes, J. A., Scapim, C. A., Braccini, A. L., Vidigal Filho, P. S., Sagrilo, E. \& Mora, F. (2005). Adubações orgânica e mineral, produtividade do milho e características físicas e químicas de um Argissolo Vermelho-Amarelo. Acta Scientiarium Agronomy. Maringá, 27 (3), $521-529$.

Hoffmann, F. I., Jasper, M., Scremin, A. L. T. (2015). Avaliação de diferentes espaçamentos nos componentes de produção no milho (Zea mays L.). Revista da União Latino-americana de Tecnologia, 3, 63-88.

Junek, J. O. M. O., Lara, T. S., Paiva, M. J. A., Martins, D. B. \& Morais, C. G. (2016). Fertilizantes Organominerais. Instituto de Ciências da Saúde, Agrárias e Humanas (ISAH). 04 p. http://site.uniaraxa.edu.br/wp-content/uploa $\neg$ ds/2014/09/fertilizantes-organominerais.pdf.

Kotschi, J. (2013). A soiled reputation -Adverse impacts of mineral fertilizers in tropical agriculture. AGreCol - Association for Agriculture and ecology. Fundação Heinrich Böll, Berlin.

Lima, L. M. \& Menezes, J. F. S. (2014). Camas de frango tratadas com condicionadores na adubação da cultura do milho e da soja. Getec, 2 (4), 63-70.

Manfron, P. A., Neto, D. D., Pereira, A. R., Bonnecarrère, R. A. G., Medeiros, S. L. P. \& Pilau, F. G. (2003). Modelo do índice de área foliar da cultura do milho. Revista Brasileira de Agrometeorologia, 11 (2), 333-342.

Mata, J. J., Da Silva, J. C., Ribeiro, J. F. Afférri, F. S., Vieira, L. M. (2010). Produção de milho híbrido sob doses de esterco bovino. Pesquisa Aplicada \& Agrotecnologia, 3 (3), 333-342.

Minolta (1989). Camera Co. Ltd., Chlorophyll meter SPAD-502. Instruction manual. Osaka: Minolta Radiometric Instruments Divisions. 22 p.

Montenegro, A. A. A., Abrantes, J. R. C. B., De Lima, J. L. M. P., Singh, V. P. \& Santos, T. E. M. (2013). Impact of mulching on soil and water dynamics under intermittent simulated rainfall. Catena, 109 (2013), 139-149.

Nunes, W. A. G. A., Menezes, J. F. S., Benites, V. M., Junior, S. A. L. \& Oliveira, A. S. (2015). Use of organic compost produced from slaughterhouse waste as fertilizer in soybean and corn crops. Scientia Agricola. 72 (4), 343-350.

Pauletti, V., Barcellos, M., Motta, A. C. V., Serrat, B. M. \& Santos, I. R. (2008). Produtividade de culturas sob diferentes doses de esterco líquido de gado de leite e de adubo mineral. Scientia Agraria, 9 (2), 199-205.

Pereira Junior, E. B., Hafle, O. M., Oliveira, F. T., Oliveira, F. H. T. De. \& Gomes, E. M. (2012). Produção e qualidade de milho-verde com diferentes fontes e doses de adubos orgânicos. Revista Verde de agroecologia e desenvolvimento sustentável.7 (2), 277-282.

Pereira, M. A. M., Pereira, A. L. S., Mendes, R.T., Santos, R. B. \& Pelá, A. (2012). Adubação Organomineral na Cultura do Milho sob Cultivo Consecutivo. XXIX Congresso Nacional de Milho e Sorgo.

Raij, B. V., Cantarella, H. Quoaggio. J. Á. \& Furlani, A. M. C. (1997), Recomendações de adubação e calagem para o estado de São Paulo. Boletim 100.

Rodrigues, T. R. D., Broetto, L. Oliveira, P. S. R. \& Rubio, F. (2012). Desenvolvimento da cultura do milho submetida a fertilizantes orgânicos e minerais. Jornal Bioscience, 28 (4), 509-514.

Santos, H. G., Jacomine P. K. T., Anjos, L. H. C., Oliveira, V. A., Lumbreras, J. F., Coelho, M. R., Almeida, J. A. Araujo Filho, J. C., Oliveira, J. B. \& Cunha, T. J. F. (2018). Sistema Brasileiro de Classificação de Solos. Brasília: Embrapa, 5 ed.

Silva, T. R., Menezes, J. F. S., Simon, G. A., Assis, R. L., Santos, C. J. L. \& Gomes, G. V. (2011). Cultivo do milho e disponibilidade de P sob adubação com cama-de-frango. Revista Brasileira de Engenharia Agrícola e Ambiental, 15 (9), 903-910.

Souza, T. R., Salomão, L. C., Andrade, T. F., Boas, R. L. V. \& Quaggio, J. A. (2011). Medida indireta da clorofila e sua relação com o manejo da adubação nitrogenada em plantas cítricas fertirrigadas. Revista Brasileira de Fruticultura, 33 (3), 993-1003.

Valderrama, M., Buzetti, S., Benet, C. G. S., Andreotti, M. \& Teixeira Filho, M. C. M. (2011). Fontes e Doses de NPK em milho irrigado sob plantio direto. Pesquisa Agropecuária Tropropical, 41 (2), 254-263.

Vale, K. S., Pereira Junior, E. B., Sousa, J. X., Estevão, M. J. P., Barbosa, J. C. S. \& Rolim, H. O. (2015). Influência da adubação química e orgânica no crescimento inicial e acúmulo de nutrientes em variedade de milho crioulo. Revista Verde, 10 (1), 88-95. 